\title{
Autoformação Política em Pesquisa Social: Intencionalidades Duradoras e a Prioridade do Local
}

\section{Political Self-Formation in Social Research: Lasting Intentionality and Local Priority}

\author{
Marcio Sá \\ Universidade Federal de Pernambuco - UFPE - Brasil \\ marciodesa@gmail.com \\ ORCID: 0000-0002-1001-8381 \\ Pedro Lincoln C. L. De Mattos \\ Universidade Federal de Pernambuco - UFPE - Brasil \\ pedrolincoln@gmail.com \\ ORCID: 0000-0003-4319-2965
}

\author{
Amon Barros \\ Escola de Administração de empresas de São Paulo - EAESP/FGV- Brasil \\ amon.barros@fgv.br \\ ORCID: 0000-0002-9748-7788
}

\section{Alessandra de Sá Mello da Costa}

Pontifícia Universidade Católica do Rio de Janeiro - PUC-Rio - Brasil alessandra.costa@iag.puc-rio.br ORCID: 0000-0003-3207-2888

\section{Resumo}

Submetido em 29/08/2018; Aprovado em 26/09/2018 (Texto convidado)

Nos textos aqui reunidos são registradas falas proferidas num debate que tomou como ponto de partida uma provocação: pesquisadores e pesquisadoras estão em processo permanente de formação. Após uma apresentação geral do debate e de ideias inscritas nas expressões autoformação política e intencionalidades duradouras naquele processo, seguem-se três textos, explorando três diferentes caminhos. No primeiro deles, recuperam-se experiências de atuação enraizada numa microrregião específica e de impacto significativo na autoformação política de quem que as vivenciou. No segundo, guiado pela questão "por que temos dificuldade de estruturar projetos de pesquisa para contextos e agentes locais?", discutese porque o local pode ser enfrentado como um desafio epistemológico. No terceiro, reflete-se, sobre as tensões de se construir uma trajetória internacional que permaneça fazendo sentido e dialogando com o local. Por fim, um ponto de vista da audiência encerra a discussão. 0 texto sumariza as reflexões provocadas pelo debate e o que pode ficar para acadêmicos e acadêmicas.

Palavras-chave: Autoformação de pesquisadores; Saber Local; Internacionalização na carreira acadêmica

\footnotetext{
Abstract

The texts reproduce three lectures that took place at the V Brazilian Conference for Organization Studies. The presentations took a provocation as a start point: researchers are permanently developing themselves. After an introduction of the debate and the ideas of political self-formation and long-term intentions in that process, three paths are explored, each one in a text. First, we present an academic action rooted in the local context in a microregion of the Brazilian Northeast. The text record the impact of those actions in the political self-development of those who experienced them. Secondly, the question "why we have difficulty in structuring research projects for local contexts and agents?" guides the discussion on the reasons for the local to be faced as an epistemological challenge. In the third manuscript, there is a reflection on the tensions to build a meaningful international career experience keeping a
} 
dialog with the local. After these texts, the point of view of the audience closes the records of the debate, summarizing the discussion and bringing some new reflections.

Keywords: Academics self-development; Local knowledge; Internationalization in academic career

\section{Apresentação}

\section{Marcio Sá, Pedro Lincoln C. L. De Mattos e Amon Barros}

No IV Congresso Brasileiro de Estudos Organizacionais (CBEO) foi promovido um debate intitulado "Habitus, antes que método, de um pesquisador 'político'", que acabou por ficar registrado em dossiê específico da Revista Brasileira de Estudos Organizacionais (v. 3, n. 2, 2016, disponível em: https://rbeo.emnuvens.com.br/rbeo/issue/view/11/showToc). Nele procurou-se "explorar teoricamente como o conceito bourdieusiano de habitus poderia inspirar, orientar, justificar e por em bons trilhos a prática de um pesquisador que se sente, enquanto tal, participante de uma pólis".

Este fórum registra um segundo debate ocorrido no V CBEO (Curitiba, agosto de 2018), que deu seguimento ao anterior, reúne reflexões de pesquisadores a partir de três experiências distintas - uma de atuação local, outra de formação de pesquisadores e uma terceira em internacionalização - e visa levar adiante o debate sobre sentidos e horizontes do tipo de pesquisa que se pratica em Estudos Organizacionais (EO) no Brasil. Entendendo este campo como inserido noutro mais amplo - o da pesquisa social, que mesmo tendo ramos mais consolidados que EO, também ambienta questões semelhantes -, aqui se pretende realçar a importância de agenda de médio e longo prazo, do desenvolvimento da autoformação de pesquisadoras e pesquisadores envolvidos com os problemas de uma pólis (que, em sentido aberto, pode ser entendida como uma comunidade, um município, um estado, uma região ou um país).

O conceito "autoformação" se cruza com o de autoria, um ideal acadêmico. É a mesma ideia de selfauthorship, que se apresenta como orientação hoje muito discutida para a educação superior. Na verdade, estamos dentro da teoria geral da educação e na linha de Vygotsky e Piaget que firmaram o protagonismo do educando na sua própria formação. Humberto Maturana também chegou aí a partir do conceito biológico de autopoiesis - os seres vivos só sobrevivem na medida em que conseguem se tornar autônomos. O próprio Maturana estendeu a ideia ao mundo da educação e da cultura. Além disso, quando se fala em autoformação do pesquisador está-se diante do resgate de experiência histórica decisiva para o desenvolvimento da ciência moderna e para o seu prestígio social. Até a profissionalização da academia, como a temos hoje, um fenômeno da segunda metade do século passado, os centros de pesquisa científica fomentavam os talentos e a inovação diferenciados, e deles surgiram os nomes que até hoje de alguma forma seguimos. Estes pesquisadores têm algo em comum: tomaram o risco de trabalhar por si, com pequenos grupos de alunos colaboradores. Seguiríamos à sua luz.

As "intencionalidades duradouras", referente ao plano subjetivo do pesquisador que procura, planeja e escolhe seus projetos de pesquisa e carreira de médio e longo prazos, entram no contexto da autoformação. Elas são como fio condutor que tem o potencial de, ao se constituir, interligar avanços consistentes, capazes de costurar os sentidos do passado quando se segue adiante, pelo esforço de coerência interna que apresenta. A autoformação política exige intencionalidade duradoura, e isso está no cerne de nossas reflexões e desse debate.

Na tensão natural entre formação coletiva da instituição e autoformação do pesquisador, um horizonte a ser melhor explorado entre nós é o enraizamento local e politizado de pesquisadoras e pesquisadores. Entendemos que a pesquisa deve se ocupar de questões reais e relevantes aos praticantes (gestores, trabalhadores, cidadãos etc.), com os desafios que enfrentam em segmentos específicos da gestão pública, em associações/cooperativas, em empresas convencionais, nos negócios periféricos (e.g., negócios familiares não formalizados) ou nas atividades relacionadas ao campo da cultura popular (como o artesanato).

Embora a princípio pareça que a autoformação encontre com mais facilidade a experiência e discussões locais, é necessário pensar na articulação dessas discussões com diálogos travados internacionalmente porque a experiência internacional já faz parte indispensável da profissão acadêmica. Politicamente há pelo menos dois eixos que devem receber atenção do pesquisador como aqui o entendemos. 
De um lado, ao flertar com a academia estrangeira, é grande o risco de se estabelecer a comunicação em um não lugar, entre o local e o internacional. Além disso, vem à tona certa angústia em torno da tradução de temas, objetos e conceitos e seus efeitos na precisão da comunicação. Não sendo capaz de efetivamente dominar as técnicas de produção e disseminação de textos na arena global, o autor pode alienar aqueles que estão ao seu redor.

De outro lado, há que se considerar em que medida a pressão pela internacionalização não é também um movimento político. Traz oportunidades de avanços e de dinamismos, é certo, mas também arrisca a virar as costas para o que há de único no local. A negociação dessa tensão é também um ato que envolve posicionamentos por parte dos sujeitos, em relação às forças que envolvem as formas de investigar e de ser pesquisador.

Horizontes como estes, se institucionalizados, poderiam vir a reverberar de modo mais significativo tanto na evolução do campo quanto na autoformação daqueles que se identificam com ele. Mesmo quando não se ignora haver um "preço" a se pagar por isso, talvez o esforço íntimo de se resolver acerca de questões como as seguintes possa nos levar à promoção de práticas mais significativas, duradouras e esclarecidas: Quais são as implicações práticas de uma maior politização autoformativa? É interessante ao campo que as novas gerações tomem para si horizontes como estes acima esboçados? 0 que poderia ser promovido entre nós para fortalecê-los?

Por fim, uma ressalva. As experiências que são apresentadas a seguir não se propõem exemplares, mas todas acreditam que podem se inspirar mutuamente e, claro, inspirar (e serem inspiradas por) demais interessados neste debate. 


\section{Experiências de Autoformação Política no Agreste Nordestino}

\section{Marcio Sá}

Agreste é como se chama uma faixa de terra que, grosso modo, corta o Nordeste do Rio Grande do Norte até a Bahia. Zona de transição geoclimática, por um lado se avizinha do Sertão, dos significados que ele adquiriu no imaginário nacional e de sua identidade cultural que alguns se orgulham e fazem questão de manter. A mesma da qual outros se envergonham, em particular, ao enfrentarem socialização em centros urbanos maiores. Por outro lado, se conecta com as capitais litorâneas, centros regionais que servem como referência da modernização periférica naquele contexto e funcionam como mediadores dos padrões culturais das metrópoles mundiais. Entre um e outro, também é possível experimentar o sentido figurativo do agreste, ou seja, o que é áspero, rústico, não cultivado.

Foi na objetividade de Caruaru, curiosamente chamada por muitos de "capital do Agreste", que passei a viver e atuar como professor-pesquisador na UFPE, isso já faz quase doze anos. Cheguei por lá fugitivo do modo frenético e truncado por meio do qual vi Recife se tornar uma metrópole, cada vez mais incômoda de se coabitar, transitar... E "me encontrei" como pesquisador num lugar de passagem e partilha de referências associadas às ideias de "moderno" e de "tradicional".

Naqueles dois agrestes, o objetivo e o figurado, acredito ter começado a incorporar o ofício da pesquisa social como um saber prático, que tem como lócus um contexto mais ou menos circunscrito. Paulatinamente fui compreendendo, ao praticar, que teoria, epistemologia e métodos, mesmo que em universalização pela global science quase que como commodities, precisam de ressignificação localizada em função dos desafios investigativos abraçados e, em termos políticos, do que se avalia como relevante àquela pólis.

Pouco depois de fazer morada naquele pedaço de mundo, percebi que a dinâmica de vida e trabalho por lá estava fortemente vinculada às heranças e à presença cotidiana do comércio de feira de rua. 0 insight dos feirantes e dos seus negócios de feira como objeto de estudo me veio um dia, quando ao caminhar pela própria Feira de Caruaru, fui tomado por questões que podem ser hoje formuladas nestes termos: como não voltar meus primeiros esforços investigativos na região para aquele tipo de negócio e para o modo como são administrados pelos feirantes? Como não começar uma trajetória de pesquisa localizada sem enfrentar um dos seus personagens mais emblemáticos? A partir delas se deu uma primeira vivência de pesquisa que ainda hoje me é cara e que teve seus resultados apresentados no livro Feirantes: quem são e como administram seus negócios, publicado em 2011 e com $2^{\mathrm{a}}$ edição de 2018, pela Editora UFPE (Sá, 2018a).

Da história coletiva local vinculada a este tipo de comércio, emergiu outra que transformou as casas e os quintais agrestinos em fabricos de confecções, bem como projetaram o elemento produtivoindustrial ao protagonismo nas transformações locais das últimas décadas. A outra vivência de pesquisa que me é mais significativa se voltou para seus proprietários de negócios de produção e comercialização de confecções e para o campo que criaram ao longo dessa trajetória que conformou a região neste século, seus resultados tomaram a forma de uma tese em sociologia que saiu adaptada em livro, Filhos das feiras: uma composição do campo de negócios agreste, impresso pela Editora Massangana da Fundação Joaquim Nabuco (FUNDAJ) em setembro passado (Sá, 2018b).

Estes dois trabalhos ocuparam muitos anos de minha atuação em pesquisa. Falo de ambos e desse tempo para ilustrar a ideia de intencionalidade duradoura, de agenda de médio e longo prazo, que acredito ter me norteado na articulação de temas que observei como relevantes ao devir local. Sem a expansão do olhar para além de cada um dos dois projetos, não acredito que teria conseguido costurá-los ao seguir adiante.

Ao longo dos últimos anos passei a viver uma crise bem íntima, mas que penso também ser nalgum modo e medida coletiva, ou seja, partilhada por ao menos alguns outros dentre nós que se questionam sobre: qual o sentido da atuação como professor-pesquisador de uma IFES? Além do básico, conduzir e publicar estudos sobre temas que julgamos relevantes é bastante? 0 que mais seria importante para enxergar sentido social no que fazemos?

Ao me debater com questões como essas e tentando melhor me resolver com elas, venho pensando com a expressão "autoformação política". Ao invés de aqui forjar uma definição escolástica, optei por partilhar três experiências que ilustram esforços práticos do que associo a esta noção. Antes disso, ressalvo que todas não podem ser consideradas propriedade individual, afinal, são partilhadas e 
construídas com outros, naquele contexto. Por um lado, são relativas e limitadas a isso. Por outro, encontram na alteridade, nos demais membros da pólis, a fonte mais substantiva de sua relevância autoformativa e sua maior possibilidade de construção de sentido para tais práticas, naquele solo.

No final de 2015 me aproximei do Centro de Educação Popular Assunção, o CEPA, uma ONG que tem como foco contribuir com a formação de crianças e adolescentes em situação de vulnerabilidade no subúrbio da cidade. Após um período de afastamento para capacitação, sentia necessidade de retomar contato com o "chão das ONGs" locais, em particular por voltar a lecionar a disciplina de Gestão Social. Apresentei uma proposta de assessoria a sua gestão que tomou forma de um projeto de extensão em curso até hoje. Muito mais do que fonte de desafios práticos da gestão de organizações sem fins lucrativos, a experiência de envolvimento direto com os dilemas enfrentados por uma organização desta natureza vem sendo marcante. As reuniões da diretoria do CEPA, das quais participo na condição de assessor, se mostram fonte de aprendizados substantivos, sobre debate honesto de opiniões e prevalência do melhor argumento, que não somente procurei partilhar em sala de aula como também cativo em mim.

Por um lado, dialogar com pessoas que dirigem uma ONG no subúrbio de Caruaru, sobre seus problemas e as possíveis alternativas para solucioná-los, possibilitou melhor abrigar, em minha atuação profissional, questões inerentes a comunidades mais vulneráveis. Por outro, a oportunidade de interagir com pessoas que escutam com atenção e valorizam minhas opiniões, sobre o fazer delas, me nutriu com um novo sentimento de utilidade e realização. Os dirigentes do CEPA costumam dizer que a entidade é um espaço formativo não somente para os filhos e filhas das comunidades atendidas, mas também para quem nela trabalha ou se associa, assim vem sendo comigo.

A segunda experiência com a qual pretendo ilustrar a noção de autoformação política é a do Grupo de Estudos e Intervenções do Agreste, o GEIA. Com cinco colegas professoras, um técnico-administrativo $^{1}$ e estudantes do Centro Acadêmico do Agreste, tive a oportunidade de participar da criação desse grupo, que tem como proposta não somente estudar, mas também intervir no meio do qual foi gestado e no qual se insere. Desde seu início o GEIA vem sendo pensado não como um grupo de pesquisa convencional, mas sim como um coletivo de pessoas que se observam nalguma medida em formação e que desejam se envolver com projetos de impacto social local, quer esses tenham mais ênfase na pesquisa ou na extensão universitária. Uma das ideias que governam o grupo é, além de conferir o mesmo status aos dois tipos de atividades, algo que pode ser visto ao se acessar a aba "projetos" do nosso site (https://www3.ufpe.br/geia/), integrá-las cada vez mais.

Assim como o anseio de intervir, também se procurou inscrever o interesse partilhado pela região, como lócus de atuação profissional, na sua própria denominação. Privilegiar o local, mas sem torná-lo algo exótico ou singularizá-lo, tanto nos permite manter como horizonte comparativo outros contextos mais ou menos periféricos nos quais se dão fenômenos similares aos de nosso interesse, quanto não cair num tipo de "fundamentalismo do local", ao qual não se deseja aderir. Acredito que usar o termo agreste como metáfora para pensar contextos periféricos pode ser fértil também para outras localidades que com ele partilham "parecenças de família", para não deixar de usar a expressão do filósofo de Viena (Wittgenstein) tão caro ao Prof. Pedro Lincoln.

A terceira e última experiência é ainda mais recente, acontece no âmbito da pesquisa "A gente e o negócio do barro: dilemas e perspectivas da comunidade artesã no Alto do Moura do século 21", sob minha coordenação e que vem contando com o valoroso empenho de três professoras (Denise Souza, Jéssica Rani e Myrna Lorêto) e três estudantes (Bárbara Leal, Shirley Silva e Maria Raíza Ferreira) que compõem a equipe de trabalho.

Originalmente um povoado rural um tanto distante do centro urbano do município, não somente em termos geográficos, mas também por seu modo de vida comunitário, o Alto do Moura, a terra dos bonecos de barro do Mestre Vitalino, vem convivendo com tensões inerentes à instalação de loteamentos e conjuntos habitacionais, no entorno do núcleo onde se encontram as casas-oficinas das famílias vinculadas à atividade artesanal, e até mesmo um distrito industrial nas proximidades. As dificuldades de manutenção econômica por meio do artesanato, o desengajamento das novas gerações que optam ou necessitam buscar outra fonte de renda, além de um crescente número de ocorrências criminais, que se associa à sensação coletiva de insegurança, são apenas algumas das tensões que lá emergiram de uns tempos para cá.

${ }^{1}$ As Professoras Denise Souza, Elisabeth dos Santos, Myrna Lorêto, Ana Márcia Pereira, Cláudia Freire e o técnico-administrativo Wagner Rocha Gomes, pesquisador que também atua como docente no ensino superior privado. 
As tensões incorporadas pelos membros-proprietários de negócios periféricos daquela comunidade é o modo como hoje está inscrito o objeto da pesquisa. Se, por um lado, tem em sua gênese a mesma intencionalidade das duas anteriores, ou seja, melhor compreender a condição de pessoas, com trajetórias de vida vinculadas às camadas sociais mais populares, que precisam ou optam por ter como fonte de renda um negócio próprio, isso, claro, sem que se tenha formação em gestão. Por outro, esta terceira pesquisa também se voltou para um horizonte prospectivo: construir e sistematizar com a comunidade diretrizes para uma agenda de prioridades, tanto a serem pleiteadas junto ao poder público quanto a nortear a atuação da Associação dos Artesãos em Barro e Moradores do Alto do Moura.

Foi assim que, por exemplo, no roteiro das entrevistas com o público pesquisado, inserimos questões do tipo: Quais melhorias o(a) Sr(a) gostaria de ver no bairro nos próximos anos? 0 que a comunidade poderia fazer para que elas se tornem realidade? E o que a prefeitura poderia fazer? Além do público direto, também escutamos alguns formadores de opinião sobre questões do tipo: 0 que imagina como políticas públicas pertinentes para a melhoria da qualidade de vida da comunidade? Aos seus olhos, o que mais ela precisa?

Ao colhermos e processarmos tais informações, elaboramos uma agenda a partir do que foi indicado pelos entrevistados, contemplando também algumas observações da equipe, organizada em função de quatro eixos temáticos: (1) cultura de valorização do artesanato e desenvolvimento do negócio coletivo; (2) saúde coletiva; (3) segurança; e (4) infraestrutura. A partir disso elaboramos um relatório técnico-parcial (Sá, et al., 2018), que foi primeiramente apresentado à associação dos artesãos e dos moradores, depois à presidência da Fundação de Cultura e Turismo de Caruaru e a um membro da Câmara de Vereadores, bem como está disponibilizado no site do GEIA. A partir de sugestão da então presidente da Fundação, foi feita uma apresentação pública do referido relatório em 27.08.2018. Assim como as anteriores, esta frente de atuação é bem recente e segue em curso.

Diante disso tudo, talvez uma implicação crucial ao pesquisador que vive tais experiências é a necessidade de "sair dos muros" das universidades e se misturar mais com os personagens da "vida real" e seus dramas, conviver e ver como pode se envolver com suas questões. Ao menos vem sendo assim que sigo procurando outros sentidos para a minha formação e atuação, lá nos outros, na pólis na qual nos inserimos é possível encontrar pistas para uma aproximação atenta e escuta genuína dos desafios cotidianos enfrentados por praticantes localizados.

Talvez esteja a encher os ouvidos de vocês com coisas um tanto óbvias já professadas, mesmo que muitas vezes não praticadas, o que me conforta foi que busquei fazer no sentido contrário, ou seja, dizêlas a partir das contingências e limitações dessas experiências agrestinas. 


\title{
Formação Acadêmica Convencional e Autoformação Política: Por que Temos Dificuldade de Es- truturar Projetos de Pesquisa para Contextos e Agentes Locais?
}

\author{
Pedro Lincoln C. L. De Mattos
}

1.

A palavra (ideia) que me seduziu a participar desta Sessão Livre foi "autoformação". Peço-lhes para marcar isso, em primeiro lugar.

Porque, quanto mais nosso sistema de pós-graduação se institucionaliza em exigências de qualidade, de produção, de ascensão na carreira e de submissão a regras de avaliação externa na pós-graduação, mais as condições de conformação prevalecem sobre as de autoformação. A tradição científicoacadêmica em que você se inseriu é forte, envolvente, abrangente, normativa. Em linguagem coloquial, eu diria: "o sistema te leva, mesmo te dando algumas oportunidades de escolha; ele se encarrega de você, mas vai te cobrar conformação; ninguém ali te falará de você formando você". E talvez por isso poucos pensam sobre si próprios depois de dez, quinze, talvez vinte anos de carreira! Contudo, há sim, a possibilidade real de identidade de carreira acadêmica!

Vou insistir. Academicamente falando, quem é você, mestrando, doutorando, ou jovem mestre, jovem doutor? Está feliz com seu Lattes? (Não perguntei se você está orgulhoso/a do quanto já contabilizou ali.) Alegre-se com seus êxitos, tudo bem! Mas onde você quer chegar com isso? Porque ser apenas um bom "professor-funcionário", já deveria ter ficado para trás, superado. Certamente você visa ao conhecimento e reconhecimento de seus pares, expresso nos convites para ensinar tal disciplina, para participar daquela banca, daquele evento acadêmico, para avaliar manuscritos e ter seu nome em periódicos e livros rodando por aí. De novo, tudo bem, maravilha! Pode sonhar com isso! Não há ego que não seja seduzido nem auto estima que não se reforce com essas recompensas ao acadêmico dedicado.

Mas este lugar aqui é diferente em relação a outras profissões. 0 mundo do conhecimento tem alma e ela vive de duas coisas: tentativas de criar algo novo e dedicação em formar alguém mais jovem. A essência do mundo acadêmico é a participação em pesquisas-desafio e a orientação de novos alunos. Pois bem, o ponto hoje aqui é o seguinte: a essas duas coisas só se tem acesso pela autoformação.

Disse, acima, coloquialmente, que o sistema se encarrega de você, que te leva e vai te dar os títulos de mestre e doutor, cumpridas as exigências; você se inscreve na seleção, atende condições, consegue o cargo e agora é professor. Parabéns! Mas, se, por trás disso, não tiver acontecido uma condução única e intransferível do despertar pessoal, terá faltado a seiva, é madeira morta na construção de uma instituição acadêmica. Não haverá o prazer de criar pesquisa nem a maturidade e o testemunho necessários à orientação de alguém menos experiente.

0 título desta Sessão Livre ofereceu dois horizontes para a autoformação: projetos acadêmicos pessoais sustentados no longo prazo (intencionalidades duradouras) e a orientação para o local. 0 primeiro são escolhas honestas e criteriosas nas quais a intenção vale mais que os termos (o projeto). 0 segundo, força você a mirar fora da academia, a não fugir à politicidade (responsabilidade política), e ao mesmo tempo pode libertá-lo da tendência à insulação ali congênita - a academia tende a bastar-se, já tem hoje como viver bem, tendo a si própria como principal referência.

Isso, para deixar bem marcado o sentido do tema desta sessão e o que nela me atraiu.

2.

Nesse contexto, dei-me uma questão específica: Por que temos dificuldade de estruturar projetos de pesquisa para contextos e agentes locais?

Parto da constatação de que o treinamento teórico e metodológico que as instituições acadêmicas nos oferecem geralmente não habilita (e talvez nem motive) para a participação social. 0 processo transformativo pessoal da autoformação implica promover reflexão esclarecedora mais profunda sobre certos pressupostos e critérios metodológicos que, em nossa formação, determinam o vetor de nossa prática de pesquisa e, de certa forma, nos inabilitam a estruturar criativamente projetos de pesquisa para contextos e agentes "localizados".

Sugiro a consideração sobre dois ou três daqueles pressupostos metodológicos e tentarei limitar meu argumento ao público de Estudos Organizacionais, objeto do CBEO. (Dado o tempo aqui disponível que me impede estender-me em exemplos, peço que cada um imagine um caso, um contexto local qualquer que gostaria de pesquisar.) 
Primeiro pressuposto metodológico. No paradigma vigente entre nós, admitidas as dissidências, a pesquisa surge de um contexto teórico supostamente interpretativo do mundo local e formulado como tema da pesquisa a ser feita. Vejam: o mundo surge do conceito, o local surge do não local. Parte-se do teórico como referência ("referencial teórico"); a perspectiva é dedutiva, ou seja, conceitos a aplicar a um caso.

Naquele paradigma, chega a ser difícil imaginar como não seria assim. Mas vejam o seguinte: o conhecimento do local partiria não de uma teoria da tradição científica sobre o tópico, mas de ampla recuperação informativa e de estudo histórico e antropológico deste "local".

Houve um tempo em que eu interpretei muito ao pé da letra o quase-adágio de que "um fato só fala pela boca de uma teoria". Hoje, acho que isso é um argumento montado contra a tese do valor do fato em si, tese do empirismo lógico, não uma normativa metodológica. Explico.

0 conceito "fato" surge em um contexto epistemológico vigente nos séculos XVIII e XIX, dominado pela crença na observação empírica despida do cultural e do subjetivo e, para tal, expressa em linguagem rigorosamente objetiva, geral, a matemática. A teoria surgia depois, reunindo e dando sentido a esses "fatos" (que falariam por si), a partir de sua própria lógica, as relações matematicamente claras entre eles. Isso formou uma epistemologia fechada em si, óleo que não se dilui ou adapta em outras águas, como as relações sociais e expressões humanas. É o que ainda temos hoje entre nós e que chamo "ciências de natureza". Ora, a crítica ao empirismo nestes contextos mostrou que a teoria, realmente, é que dirigia a montagem experimental onde os fatos precisavam da "boca" da teoria para "falar".

Então, em vez de chamar primeiro uma teoria para "falar" pelos nossos fatos, o local precisa ser entendido a partir de sua própria história colhida e montada por testemunhos e dados e com recurso a outros estudos de perspectiva similar. As "pedras se encaixam", ou, pelo menos, vão recusando certas maneiras de se encaixar. Significados são delineados, hipóteses-padrão são afastadas e certas teorias "convocadas" a integrar a inspiração interpretativa.

Toda a experiência da fenomenologia de Edmund Husserl, sua exigência metodológica da epoké; toda a experiência da Verstehen da sociologia weberiana, procedente da hermenêutica de Wilhelm Dilthey, têm fundamentado, nesse sentido, a dissidência do paradigma dominante nas ciências sociais em que a teoria tem que preceder o contato empírico com o mundo, no caso, os contextos locais.

Segundo pressuposto metodológico. 0 paradigma noético ou conceitual (que alguém poderia também chamar de platônico) se antepõe ou bloqueia situar-se no mundo dos contextos históricos, de ação. Uma das obras mais revolucionárias de Habermas é "Conhecimento e Interesse". Ele fez, posteriormente, reparos à ligação entre estes conceitos para ajustar-se ao passo que então havia dado na direção da filosofia pragmática da linguagem, a ela ajustando "interesse", que, no primeiro capítulo de "Conhecimento Pós-Metafísico" chamou de "motivos do pensamento" (no caso ali, pensamento ocidental). Não sei se tomando adequadamente de Habermas ou apenas parodiando-o, eu diria que o pesquisador precisa definir seu interesse (aquilo que gera e motiva) e o interlocutor de seu discurso.

Então, nossa dificuldade para estruturar projetos de pesquisa para contextos e agentes locais aos poucos se dissiparia se começássemos pela definição: quais são os nossos interesses neste caso, nesta pesquisa? Seria, por exemplo, o de formular depois uma política pública ou estratégia empresarial que precisaria entender o que vem se passando, os fatores interferentes no êxito? Isso faria convergir a pesquisa para o que, no fundo, seja o motor do nosso trabalho nesta sociedade tão... difícil, digamos. E não ser presa fácil da dispersão e do delírio que frequentemente contaminam o ar da academia.

Ora, todo envolvimento, que realiza a politicidade, pode ser formulado em termos de interesse. $\mathrm{E}$ talvez fosse o principal nesta academia que se põe entre as ciências aplicadas. Uma história, um contexto real deve montar-se a partir do interesse de quem os estuda. 0 interesse jornalístico é suficiente para excelentes pesquisas jornalísticas. 0 historiador tem seu interesse cientificamente válido. 0 mesmo para o sociólogo. E para quem pesquisa com interesses interdisciplinares como nos Estudos Organizacionais? Resposta: defina você o seu interesse específico! Ele é constituinte do significado e do método desta sua linha de pesquisa.

Um terceiro pressuposto metodológico, compondo os dois anteriores. 0 paradigma vigente é o da ciência de natureza, originado das Ciências da Natureza tradicionais e que firmaram um entendimento de "ciência" (termo já usado bem antes do Séc. XVIII). O pesquisador se coloca diante de um mundo externo, objetivado, que gira independente da mente humana; que é "natureza", não cultura. Qual é o interesse da ciência de natureza? Por princípio, o pesquisador tem que descobrir como aquele mundo supostamente é, explicar por que ocorre este ou aquele fenômeno a fim de controlá-lo, prevê-lo, utilizá- 
lo ou apenas contemplá-lo. As teorias consolidam progressivamente esse conhecimento explicativo e seu interesse, e tornam-se preditivas.

Ora, as ciências de cultura (termo de Max Weber e diversos outros cientistas) não são assim, e têm a linguagem como seu ambiente natural. Repito: as ciências de cultura humana não podem considerar a linguagem, inclusive o discurso, como instrumento de expressão, que o positivismo lógico deseja exata e de compreensão universal para as ciências de natureza, porque ali ocorrem as próprias relações sociais diferenciadas, no caso, as do local. Toda a compreensão atual da linguagem humana vai nesse sentido. Algumas tradições têm assumido o mesmo interesse e posição metodológica das ciências de natureza, sim. 0 exemplo mais próximo é o do positivismo nas ciências sociais. Mas isso tem-se mostrado insuficiente, um reducionismo da complexidade humana. Ou de uso restrito, como nos recortes intencionais dos surveys.

Nas ciências de cultura, inevitavelmente, uma cultura estuda o mundo de outra. 0 que uma ciência de natureza chamaria "relativismo" aqui é constituinte do singular e do valor do local tal como entendido individualmente por um autor. Mantendo-me com Wittgenstein sobre a compreensão única do humano pelo humano, e, de novo com Weber, o pesquisador traz em si as condições fundamentais de compreensão singular da ação social ("a intenção da ação", disse Weber). Foi também por isso que os estudos antropológicos viveram em harmonia com a sociologia weberiana.

3.

Dois quase-corolários. 1) E a teoria? 2) e o rigor científico?

A teoria seria alijada do processo? Nada disso! Mas tem seu momento metodológico próprio, que não é o primeiro. No caso, delineado o campo e clareados nossos interesses iniciais e próximos em relação a ele [nada de "objetivos gerais e específicos"!], há o momento em que um conceito já desenvolvido alhures caberia para ajudar e articular o entendimento. A teoria não entra "por cima", orientando normativamente a situação localizada, vem oportunamente ao encontro dela e do interesse da pesquisa. A cultura teórica ou comparativa do pesquisador não é desativada. Mas não é priorizada no processo. Fica como background silencioso e surge quando as peculiaridades do caso a solicitarem. Brotará espontaneamente e, ao mesmo tempo, já sob limites de adequação.

Do ponto de vista epistemológico, não é o rigor que caracteriza o científico, é o critério. Hoje a maioria dos produtos industriais exigem extremo rigor, precisão e redução da margem de erro. Sem dúvida no processo de pesquisa, deve-se exercer cuidado e manter-se em condições de justificar as decisões metodológicas. No entanto, o critério se exerce, p. ex., em distinguir outros usos dos termos que adota e ordenar (às vezes categorizar) o universo que surge à sua frente; em manter-se atento a incongruências na estrutura argumentativa, a inconsistência em procedimentos repetitivos, a vieses e crenças impertinentes ao contexto ou ao argumento. Ao contrário do rigor formal, algo mais próximo de certas linguagens, aquele exercício do critério é o lado mais científico do rigor.

\section{4.}

Assim, pela vinculação, ainda remanescente, de nossas instituições metodológicas a paradigmas infensos à pesquisa de contextos e agentes locais, explico nossa dificuldade de estruturar com segurança e legitimidade aquela pesquisa. 


\section{Atividade Acadêmica no Exterior: Desconforto Permanente e Arranjos Contingentes}

\section{Amon Barros}

Reflito sobre a internacionalização em "primeira pessoa". Começo apontando as relações entre nossos caminhos e as estruturas mais abrangentes nas quais nos inserimos. Na sequência, discuto dificuldades relacionadas ao domínio da língua, mas também à produção de um texto que atende a outras regras. Esse engajamento, no meu entendimento assume forma de jogo. Acho que é uma contribuição a um diálogo que já vem acontecendo e retomando ânimo (e.g. Goulart, 2018; Rossoni, 2018).

Na vida acadêmica, a passagem pelo exterior é sempre um evento individual e de autoformação. Quando entrei na faculdade, nem imaginava a possibilidade de viajar para fora do país. A primeira vez que voei de avião foi para uma entrevista de estágio numa companhia aérea em 2005. A segunda, para ir a um congresso no Rio. No início da pós-graduação, não me imaginaria tendo a oportunidade de cursar parte doutorado no Reino Unido. Tive o desafio e a oportunidade de fazer o sanduíche em Lancaster. Isso só foi possível pela bolsa da Fundação de Amparo à Pesquisa do Estado de Minas Gerais (FAPEMIG) e o apoio de amigos e familiares.

Quando me formei, não me via atuando em São Paulo e tendo a oportunidade de frequentar congressos pelo mundo. Hoje, graças as oportunidades dadas pela FGV EAESP, pude ir a algumas das principais conferências da área e ocupar o Division chair track, junto com a Fernanda Sauerbronn.

Enfatizo, que todos os caminhos que vamos tomando obviamente são parte de nossa autoformação. Mas, o modo como os trilhamos não é fruto apenas de nossas escolhas. É fruto das condições que nos são colocadas pela realidade em que estamos inseridos - fazendo aqui um mal arremedo de Marx (1988).

A predileção pelo local é um aspecto importante para o pesquisador que reflete sobre as condições de produção do próprio conhecimento. Também, para quem acredita que nós pensamos aonde somos (Mignolo, 2011). Embora, talvez, o contrário não seja verdadeiro, tendo em vista que pensar como o outro não nos torna um deles.

Há uma relação de tensão entre a reprodução, a mímica ou o abandono do modelo estrangeiro. Este é um dos aspectos estruturantes da ideia de internacionalização tal como posta para os pesquisadores. Órgãos de controle e entusiastas querem reproduzir, apropriando-se das práticas de pesquisa e escrita. Contudo, boa parte dos pesquisadores só consegue fazer mímica, traduzir um texto ou um periódico, mas permanecendo estrangeiro aos padrões externos. Ao mesmo tempo, há outro grande grupo que abandona esse engajamento por considera-lo absurdo. 0 caminho entre os três modelos e o lugar onde se chega é, em última instância, construído em larga medida pelo pesquisador.

Entretanto, nenhuma das alternativas é satisfatória. Nenhuma abarca a complexidade de se situar o pensamento dentro das dinâmicas de sua produção e disseminação. 0 pensamento e sua circulação não se dão apenas em espaços abstratos. Mas, também na academia que existe e é (re)produtora de hierarquias ensejadas pelas desigualdades inerentes ao sistema econômico e social. É aquela pergunta que sempre ouço nos congressos "o que você [brasileiro] está fazendo aqui?"

Isso não quer dizer que o diálogo com a academia internacional seja impossível. A comunicação é possível, mas sempre imperfeita. As relações de produção e as condições de disseminação de conhecimento não se dão em condições de igualdade. Para ir ao "estrangeiro" algum desenraizamento é condição necessária. 0 afastamento do local e algum desapego é a única forma de se livrar de certos hábitos e formas de fazer que perpassam a constituição dos sujeitos que sempre se dá no local.

Entretanto, esse esforço não soluciona o problema de tradução das ideias locais para o contexto internacional. Devemos considerar a barreira da língua. Mas, adicionalmente deve-se entender que o que se lê decorre de um processo mais complexo que ultrapassa a acessibilidade linguística do texto. Como toda prática a pesquisa é construída a partir de processos compartilhados. Muitas vezes, difíceis de serem objetivados para que possam ser propriamente transmitidos. A complexidade talvez, possa ser exprimida a partir de Pessoa (1999): “Minha pátria é minha língua”. Ou, mais especificamente:

Falar é estar em condições de empregar uma certa sintaxe, possuir a morfologia de tal ou qual língua, mas é sobretudo assumir uma cultura, suportar o peso de uma civilização. [...] existe na posse da linguagem uma extraordinária potência. [...] Todo povo colonizado - isto é, todo povo no seio do qual nasceu um complexo de inferioridade devido ao sepultamento de sua originalidade cultural - toma posição diante da linguagem da nação civilizadora, isto é, da cultura metropolitana. Quanto mais assimilar os valores culturais da metrópole, mais o colonizado escapará da sua selva (Fanon, 2008, p. 33-34). 
Assim, é impossível que o pesquisador ou a pesquisadora escape dos efeitos desse contato linguístico, que vai além do mero domínio do idioma. Ele passa também pela estrutura e pelas expectativas em relação ao texto científico. Como Derrida (1995) ensina em relação ao arquivo, a materialização das práticas é enquadrada pela forma como elas podem ser registradas.

Nesse sentido, o pesquisador e a pesquisadora também são produzidos nessa interação com ethos, modelos de investigação e possibilidades de escrita. E esse ethos não é transmitido pelo treino desinteressado. É preciso jogar para valer. É a experiência que permitirá transformar essa relação com a língua e entender de forma vivida sua ambiguidade e seus efeitos prolongados. Traduzir uma ideia para tornála compreensível não é só verter um texto de uma língua à outra. É um processo que envolve um aprendizado que dificilmente é transmitido fora da prática.

Seguindo Butler e Spolestra (2012) vemos que Gadamer em “Verdade e Método" (1975) afirma que o jogo é sempre um risco para o jogador. Isso, porque para cumprir com os objetivos do jogo, as pessoas devem abrir mão de sua liberdade e aceitar que as regras do jogo transformem seu comportamento intencional. Assim, não há como o jogo não transformar o jogador.

Por exemplo, traduzir a língua do texto não é suficiente para sua aprovação num congresso ou periódico. As palavras são apenas parte da comunicação que envolve também aspectos contextuais. Quando se submete um texto (palavra interessante, inclusive) se instaura um jogo e uma negociação com quem vai avaliar seu texto. Desde o primeiro momento, tendem a reconhecer você como não-nativo. E, nesse processo de diálogo com os avaliadores as formas de escrita e fazer acadêmicos são negociadas e desafiadas, o que não é só um processo instrumental de edição de texto, mas é também um processo ético que envolve uma negociação ética de até onde você aceita ir. Esse processo talvez seja mais marcante para quem tenta a vida fora, mas é parte de qualquer processo de publicação também no Brasil.

Durante o trajeto, essa dupla tradução desafia pesquisadores a enquadrar o local no que interessa ao internacional, e tornar o internacional significativo para o local. Esse movimento demanda uma reflexividade elíptica, de tradução entre um mundo e outro. Esse processo pode permitir encontros significativos, mas também abre espaço para negociar identidades que são colocadas em xeque. Uma espécie de porta voz do outro aonde quer que se vá e, assim, um deslocado permanente. Esse processo pode gerar aprendizados, mas também é fonte de instabilidades nos nossos posicionamentos que tem que ser permanentemente negociados. "O sertão é sem lugar" (Rosa, 1982)

Assim, a academia funciona largamente como um jogo. Suas regras vão diferir de acordo com o lugar em que o sujeito se situa: regional, nacional; este ou aquele internacional. Há uma persona que atua com objetivos em seguir certar regras e buscando se manter atento aos movimentos do jogo. Não digo que acadêmicos e acadêmicas seja meros falseadores de si, mas que só podem atuar reconhecendo as (diversas) regras e integrando-as em suas práticas. Como diz Gadamer o artista é diferente do jogador pela consciência de sua condição artificial, na medida em que atua para ser visto por um outro. Jogadores ou artistas?

Aqui, quero enfatizar que a academia é jogo. Mas, também, que ela pode ser jogo coletivo. Não me refiro aqui à (co)autoria cerimonial, uma questão complexa e que mereceria uma discussão à parte. Mas, à ideia de que ainda que em vários momentos o ambiente acadêmico pareça hostil, ele não precisa ser. Acho que é importante sempre nos engajarmos numa análise de nossos comportamentos: a generosidade, a empatia e o respeito ao outro são alguns traços de comportamento que devemos buscar, cultivar e reconhecer.

A carreira acadêmica, ainda que marcada por certa solidão do pesquisador em atividade, é impossível se pensada fora de sua comunidade. A construção do conhecimento é feita em diálogo e, por isso, nossas ideias devem ser publicadas. Além disso, todo reconhecimento acadêmico passa pela legitimidade atribuída por seus pares. Que o acadêmico possa se engajar com os seus colegas de forma puramente instrumental, torna isso mais triste, mas não menos verdadeiro.

Não é só a letra do texto que tem que ser traduzida, mas também sua forma e seus focos. Isso significa que os dados têm que ser subsumidos e transmutados em teoria, talvez arrancando parte de suas raízes ou tentar torna-los em experiência "universal". 0 "sertão é dentro da gente" (Rosa, 1982)

De toda maneira, concluo que entre o quintal e o mundo há cercas, mas também há possibilidade de se construírem pontes, pela qual o encontro de pessoas com seus múltiplos interesses, ideias e complexidades pode acontecer. Como disse Manoel de Barros: 
Prezo a velocidade

das tartarugas mais que a dos mísseis.

Tenho em mim um atraso de nascença.

Eu fui aparelhado

para gostar de passarinhos.

Tenho abundância de ser feliz por isso.

Meu quintal é maior do que o mundo.

Sou um apanhador de desperdícios 


\section{De um Ponto de Vista da Audiência: o que Pode Ficar de um Debate Como Esse?}

\section{Alessandra de Sá Mello da Costa}

O convite feito para tecer alguns comentários sobre o fórum, a partir do ponto de vista da audiência, foi aceito na hora. De imediato. E o que me levou a aceitar essa tarefa arriscada foi a oportunidade percebida de poder compartilhar algumas ideias que iam passando pela minha cabeça conforme os palestrantes iam se sucedendo na dinâmica em curso. Espero que as minhas reflexões e inquietações contribuam para desdobramentos futuros do debate.

Conforme as três experiências iam sendo narradas (de atuação local, de atuação internacional e de formação de pesquisadores) eu fui criando contrapontos e analogias com a minha própria trajetória. A reflexão que primeiro surgiu foi sobre a relação entre autoria e pesquisa social. Ouvir do Marcio Sá sobre as suas experiências de autoformação política no agreste nordestino e de "sair dos muros das universidades" me levou a questionar se as minhas pesquisas possuem implicações políticas e o quanto a minha autoria fica entrincheirada em uma zona de conforto de uma universidade particular na zona sul carioca. Sempre asseguro para meus alunos e alunas que pesquisamos porque queremos mudar o mundo. Quais seriam, no entanto, os limites ou fronteiras da minha atuação neste mundo como pesquisadora? Quais limites imponho à minha autoformação? Quais limites apresento às pessoas que trabalham e pesquisam comigo? Até onde posso ir com as minhas inquietações? Até onde me permitem ir com as minhas inquietações?

Eu busco respostas para essas indagações de forma recorrente no meu dia a dia em função das pesquisas que venho desenvolvendo, nos últimos anos, no âmbito do grupo Pesquisa Histórica em Administração. Estudo memória, história e organizações em uma perspectiva bem particular para a área de estudos organizacionais. Por meio de acervos e arquivos da repressão e da resistência (no Brasil e na América Latina) me interessa compreender e problematizar as relações entre empresas, governo e sociedade em regimes ditatoriais; a constituição de espaços organizacionais de memória de resistência e de liberdade; a trajetória de empresas que historicamente violam os direitos humanos dos seus trabalhadores; e práticas organizacionais que subsidiam violência, tortura e repressão. Sempre a partir de fontes documentais sensíveis que são difíceis de pesquisar, em todos os sentidos.

Em termos de formação e autoformação política, acredito que os meus desafios também sejam os desafios dos pesquisadores e pesquisadoras (vinculados à graduação e pós-graduação de diferentes instituições e áreas do conhecimento) que fazem parte do grupo de pesquisa acima mencionado. No entanto tudo é sempre muito conversado e os limites, às vezes esgarçados. A impressão que tenho é que estamos sempre atuando nos limites e nas bordas da conformidade institucional. Mas as experiências tem sido, na maior parte das vezes, de muito crescimento pessoal.

Mas logo a seguir o meu pensamento é interrompido e quase atropelado pela fala do Amon Barros sobre a sua experiência de atividade acadêmica no exterior. Demanda atual dos Programas de Pós-Graduação e das agências reguladoras e de fomento, o dialogo com o outro é importante e faz parte da trajetória de formação e autoformação de pesquisadoras e pesquisadores. No entanto, como muito bem colocado pelo pesquisador, esta experiência é permeada por "desconfortos e arranjos contingenciais". Quando ele enuncia que o diálogo com a academia internacional não é impossível, apesar de imperfeito, na mesma hora eu penso: como estabelecer uma relação dialógica com uma academia internacional onde a prioridade do local não adquire importância? Como já disse, os meus interesses de pesquisa são orientados para questões locais - nacionais e latino-americanas. Mas dialogar com o estrangeiro não precisa ser, necessariamente, sinônimo de diálogo com a academia norteamericana e/ou europeia. A atividade acadêmica internacional pode ser estabelecida com países mais próximos do nosso contexto social, político, econômico, cultural e histórico. Por exemplo, Argentina, Chile e Uruguai.

"Você está feliz com seu Lattes?". Pronto. Na última fala do fórum, prof. Pedro Lincoln provoca a audiência com esta pergunta. Nos lembra que o mundo do conhecimento tem alma, pergunta aonde queremos chegar e nos ensina que apesar das "condições de conformação prevalecerem sobre as de autoafirmação" é possível a construção de uma "identidade de carreira acadêmica". Mas como eu negocio estas tensões? Quais seriam os espaços permitidos para se transitar entre estas condições? Se os espaços forem estreitos, será que não faria sentido pensarmos também em condições de autoconformação? 
Enfim, o que pode ficar de um debate como esse? Com certeza muitas perguntas sem respostas imediatas. 0 tempo alocado para a troca de ideias e o compartilhamento de experiências nos eventos é - infelizmente - sempre mais curto do que o necessário. Mas acabam por nos inspirar. E espero que a minha narrativa possa ser compreendida como uma expressão desse efeito. E, buscando um último sopro de inspiração, resgato a referência feita logo no início da abertura do fórum à pólis grega (e a sua inerente demanda por atuação política) para sugerir que, em futuros encaminhamentos, sejam também contempladas as experiências de pesquisadoras. Para além do local, do internacional e dos movimentos de formação e conformação. Acredito que o debate proposto acerca dos sentidos e horizontes do tipo de pesquisa que se pratica em Estudos Organizacionais no Brasil pode ser ampliado e aprofundado trazendo também a narrativa das experiências de desenvolvimento da autoformação de mulheres pesquisadoras, trajetórias recorrentemente silenciadas pela academia nacional e internacional.

\section{Referências}

Barros, M. de. (2015). 0 apanhador de Desperdícios. In: Meu Quintal é Maior do que o Mundo: Antologia. São Paulo: Objetiva.

Butler, N., \& Spolestra, S. (2012). Your Excellency. Organization, 19(6), 891-903.

Derrida, J. (1995). Archive Fever: A Freudian Impression. Diacritics, 25(2), 9-63.

Fanon, F. (2008). Pele Negra Máscaras Brancas. Salvador: EDUFBA.

Gadamer, H.-G. (1975). Truth and Method. London and New York: Continuum.

Goulart, S. (2018). 0 conhecimento local: produção, desafios e embates. Farol - Revista de Estudos Organizacionais e Sociedade, 5(12), 268-296.

Magolda, Marcia B. (2014). Self-Authorship. New Directions for Higher Education, 166, 25-33.

Marx, K. (1988). O Dezoito Brumário de Luís Bonaparte. In: Manuscritos Econômicos e Filosóficos e Outros Textos Escolhidos, col. Os Pensadores, 4a Ed. São Paulo: Nova Cultural.

Mignolo, W. (2011). The Darker Side of Western Modernity: Global Futures, Decolonial Options. London: Duke University Press.

Pessoa, F. (1999). O Livro do Desassossego. São Paulo: Companhia das Letras, 1999.

Rosa, G. (1982). Grande Sertão: Veredas. Rio de Janeiro: José Olimpio Editora

Rossoni, L. (2018). Editorial: em defesa das publicações em português. Recadm, 17(3), I-XIII.

Sá, M. (2018a). Feirantes: quem são e como administram seus negócios. 2a ed. Recife: Editora UFPE.

Sá, M. (2018b). Filhos das feiras: uma composição do campo de negócios agreste. Recife: Massangana/FUNDAJ.

Sá, M.; Rani, J.; Silva, S.; Leal, B; Souza, D. (2018). Algumas questões do Alto do Moura no século 21. Relatório técnico-parcial da pesquisa "A gente e o negócio do barro: dilemas e perspectivas para a comunidade artesã do Alto do Moura no século 21". Caruaru: 2018 (agosto). Disponível em: www3.ufpe.br/geia. Acesso em: 24/08/2018. 